\title{
Thinking Big and Thinking Small: A Conceptual Framework for Best Practices in Community and Stakeholder Engagement in Food, Energy, and Water Systems
}

\author{
Andrew Kliskey ${ }^{1, *}$, Paula Williams ${ }^{1}{ }^{\mathbb{D}}$, David L. Griffith ${ }^{1}$, Virginia H. Dale ${ }^{2} \mathbb{O}$, Chelsea Schelly ${ }^{3} \mathbb{D}$, \\ Anna-Maria Marshall ${ }^{4}$, Valoree S. Gagnon ${ }^{5,6}$, Weston M. Eaton ${ }^{7}$ and Kristin Floress ${ }^{8}$ (D) \\ 1 Center for Resilient Communities, University of Idaho, Moscow, ID 83844, USA; \\ paulawilliams@uidaho.edu (P.W.); griffith@uidaho.edu (D.L.G.) \\ 2 Department of Ecology and Evolutionary Biology, University of Tennessee Knoxville, \\ Knoxville, TN 37996, USA; vdale@utk.edu \\ 3 Great Lakes Research Center, Michigan Technological University, Houghton, MI 49931, USA; \\ cschelly@mtu.edu \\ 4 Department of Sociology, University of Illinois Urbana-Champaign, Urbana, IL 61801, USA; \\ amarshll@illinois.edu \\ 5 College of Forest Resources and Environmental Science, Michigan Technological University, \\ Houghton, MI 49931, USA; vsgagnon@mtu.edu \\ 6 Great Lakes Research Center, Michigan Technological University, Houghton, MI 49931, USA \\ Citation: Kliskey, A.; Williams, P.; \\ 7 Department of Agricultural Economics, Sociology, and Education, Pennsylvania State University, \\ University Park, PA 16802, USA; wme107@psu.edu \\ 8 United States Department of Agriculture Forest Service, Evanston, IL 60201, USA; kristin.m.floress@usda.gov \\ * Correspondence: akliskey@uidaho.edu; Tel.: +1-208-885-6499
} Griffith, D.L.; Dale, V.H.; Schelly, C.; Marshall, A.-M.; Gagnon, V.S.; Eaton, W.M.; Floress, K. Thinking Big and Thinking Small: A Conceptual Framework for Best Practices in Community and Stakeholder Engagement in Food, Energy, and Water Systems. Sustainability 2021, 13, 2160. https://doi.org/10.3390/ su13042160

Academic Editor: Richard

A. Niesenbaum

Received: 7 January 2021

Accepted: 12 February 2021

Published: 17 February 2021

Publisher's Note: MDPI stays neutral with regard to jurisdictional claims in published maps and institutional affiliations.

Copyright: (c) 2021 by the authors. Licensee MDPI, Basel, Switzerland. This article is an open access article distributed under the terms and conditions of the Creative Commons Attribution (CC BY) license (https:// creativecommons.org/licenses/by/ $4.0 /)$.

\begin{abstract}
Community and stakeholder engagement is increasingly recognized as essential to science at the nexus of food, energy, and water systems (FEWS) to address complex issues surrounding food and energy production and water provision for society. Yet no comprehensive framework exists for supporting best practices in community and stakeholder engagement for FEWS. A review and meta-synthesis were undertaken of a broad range of existing models, frameworks, and toolkits for community and stakeholder engagement. A framework is proposed that comprises situational awareness of the FEWS place or problem, creation of a suitable culture for engagement, focus on power-sharing in the engagement process, co-ownership, co-generation of knowledge and outcomes, the technical process of integration, the monitoring processes of reflective and reflexive experiences, and formative evaluation. The framework is discussed as a scaffolding for supporting the development and application of best practices in community and stakeholder engagement in ways that are arguably essential for sound FEWS science and sustainable management.
\end{abstract}

Keywords: best practices; community engagement; conceptual framework; co-production; foodenergy-water systems; stakeholder engagement; transdisciplinary

\section{Introduction}

The expanding focus in science on big system interactions is epitomized by research at the nexus of food-energy-water systems (FEWS), also variously referred to as energyfood-water systems (EFW), food-water-energy systems (FWE), water-energy-food systems (WEF), and food-land-energy-water (FLEW) systems. FEWS science attempts to understand how food systems, water systems, and energy systems interact from social, ecological, and physical science perspectives to meet society's growing demand for food, energy, and water [1,2]. It is no longer sufficient to treat a single system in isolation; to be able to develop solutions to vexing questions of demand and availability of food, energy, and water requires explicit examination of the system-level interactions among all three sectors. "Thinking big" in FEWS refers to the expansive systems nature of food, energy, and water operating 
at broad spatial and temporal scales and the far-reaching ramifications for society of food, energy, and water, both individually and collectively. Thinking big requires addressing questions such as how does water availability, driven by climate and hydrologic conditions, support and also limit agricultural crop production and at the same time support and limit energy production, and what are the relative trade-offs and feedbacks among these systems? "Thinking small" by contrast refers to the local, community contexts in which FEWS outcomes are manifested and where potential solutions need to be applied. To be able to generate holistic knowledge that is beneficial to society, scientists increasingly recognize that they must "think small" to work hand-in-hand and partner with non-scientists if usable outcomes are to be realized [3,4]. For example, a key part of the Food and Agriculture Organization's World Economic Forum approach insists that stakeholder engagement and dialogue is critical for assessment and intervention [5].

A framework for best practices in FEWS science incorporating community and stakeholder engagement requires both thinking big and thinking small in order to accommodate systems level understanding and interactions among food systems, energy systems, and water systems at a local level, considering not only how FEWS science translates to the local spatial scale but also to the immediate time scale (the present) as well as other time scales (defined as important by stakeholders and communities themselves) as well as by ecological conditions, and to discrete social scales (a town or city or institution).

Scientific approaches that involve communities, industry, tribal organizations, nongovernmental organizations, government agencies, and other stakeholder groups have variously been called community-engaged research [6], stakeholder engagement [7], participatoryaction research [8], and transdisciplinary research [9]. Community-engaged research is distinguished from the other approaches by focusing on the importance and benefits of research to communities, where community members are instrumental in determining the trajectory of research questions, research design, and data collection and analysis [10]. Participatory-action research emphasizes the intention of empowering communities and improving community practices during knowledge creation [10,11]. Practitioners who champion stakeholder engagement take the stance that effective research in policy and practice is founded on active knowledge exchange between researchers and stakeholders during the process of knowledge co-production [7]. Examples include modeling actors, resources, their dynamics and interactions in dairy production systems [12], and assessment of progress toward landscape sustainability goals, both based on input from stakeholders [13]. Transdisciplinary approaches to knowledge co-production are based on joint ownership, responsibility, and commitment from both scientists and stakeholders [9]. Regardless of the nuance of a particular approach, they all have in common an intent to transform society by producing scientifically rigorous knowledge that is relevant to vexing social problems [14]. Engagement of Indigenous peoples in FEWS projects is of particular importance as they are often the original landscape knowledge holders, and land and water rights holders, positioned to directly contribute to the research process as well as having intimate stakes in the outcome of research.

Across the spectrum of engagement efforts [15,16], there is also a spectrum of achievements. Some efforts lead to success, some to failure, and others to varying degrees of success. Past work highlights some of the conditions that limit success as well as the importance of considering best practices for community and stakeholder engagement [17]. For example, the research of Prehoda and colleagues highlights some of the challenges of community-engaged solar energy research because community members who were engaged in research processes were distinct from decision-makers who controlled application of research findings [10].

In this paper, we define community and stakeholder engagement as involvement in the research or project, from minimally to extensively, of people or organizations other than researchers. Stakeholders can be considered as those who are directly impacted or professionally involved, while community members are those who may not have direct decision-making or be directly impacted, but whose values and priorities deserve consideration for planning so that it is more just and inclusive and ultimately better for a locality. 
It is important to note that there is a broad spectrum of engagement efforts or modes, equal footing between stakeholders and researchers is one mode, but may not always be relevant to a topic, and the spectrum of modes relates to context and other conditions of a particular project or effort [16]. Scientists may themselves be stakeholders, but in the context of engaged nexus science, they are always differentiated in terms of knowledge and structural hierarchies that require sensitivity and attention. We also recognize that both stakeholder groups and communities are composed of individuals who are diverse in their experiences and worldviews, so none of these groups can be considered homogeneous or unified in their understanding of FEWS systems or the ways these systems impact their lives and livelihoods.

Best practices are a collective set of protocols, methodological approaches and methods, theories, definitions, activities, and evaluative understanding of what did and did not work [18] in a particular field or area of inquiry. Sometimes these are called "good or better practices" because what is "best" can depend on the specific conditions and stakeholders [13]. Any good, better, or best practice should be an effective, standardized way of achieving an outcome that can work in a range of settings [19] and should be better at delivering a particular outcome than other current strategies [20]. Best practices have been developed for learning and teaching [21], technology industry incubators [20], communitybased observing [22], integrating social sciences in sustainability research [18], ecosystem management [23], and participant engagement in health and disease programs [19]. However, few coherent, singular frameworks for best practices in community-engaged research exist, within either the community engagement or environmental science literature, specific to FEWS science. There have been efforts to identify best practices around co-production of knowledge in review papers [24], but no dominant framework has emerged for identifying or disseminating best practices to support the FEWS community of practice.

A framework for best practices in FEWS science incorporating community and stakeholder engagement requires accommodating systems level understanding and interactions among food systems, energy systems, and water systems and translating FEWS science to the local spatial scale and the immediate time scale (the present). In short, FEWS science and a best practices framework require accommodating multi-scalar and inter-scalar relationships $[3,25]$ while attending to both thinking big and thinking small, seeing and empirically examining systems connections while always attending to impacts in local places and spaces.

The goal of this paper is to review FEWS related literature to assess the state-ofknowledge in community and stakeholder engagement, including contributions to date for identifying best practices, and to develop a conceptual framework for best practices in community and stakeholder engagement that can serve as the scaffolding for the FEWS community of practice. To identify best practices, we reviewed frameworks and conceptual models for stakeholder and community engagement both within and outside the FEWS literature (as described below) to capture the best framework applicable to FEWS science. This framework is intended to offer a starting point for further deliberation, testing, and refinement.

\section{A Review and Synthesis of Research on Best Practices for Community-Engaged FEWS Research}

Approaches were developed for understanding key patterns in both practices of stakeholder engagement and in frameworks for stakeholder engagement in FEWS literature. This involved a systematic review of relevant literature as described below. A systematic review is a detailed and transparent means of gathering, appraising, and synthesizing patterns [26]. A set of selection criteria were established that allowed the detection of key patterns within mostly relevant and peer-reviewed literature. Peer-review literature was used because a systematic search and review is possible using online databases, and the expectation is that peer-reviewed literature will be more rigorous than other literature. Search terms always included the words "stakeholder" or "engagement" or "community" or "nexus." These terms were modified using a separate and boolean operator for variations 
on FEWS. These were input as individual searches, for example: keyword (FEWS or food or energy or water) and keyword (stakeholder or engagement or community or nexus). The publications were selected from two different online databases: ScienceDirect and WorldCat, ensuring comprehensiveness of the review. The abstracts of each paper were reviewed to determine whether they were related either to FEWS or to stakeholder or community engagement. If the abstract was unclear, a word search was conducted for relevant secondary keywords (nexus, etc.) within the body of the articles. If there was no indication that the paper included at least one term from both boolean operators, it was excluded.

A database of 289 papers were compiled. Each paper was read and categorized as FEWS related or not, and whether it included community or stakeholder engagement. Many papers discussed the importance of stakeholder and community engagement, but did not engage either and those papers were eliminated from consideration. If the paper included community or stakeholder engagement, we also characterized the extent of engagement using the typology established in Ghodsvali et al. [4], and levels of engagement using the criteria enumerated by Fazey [21].

\subsection{Patterns in Community and Stakeholder Engagement in FEWS}

From the literature search, 289 papers were identified and subdivided into those that emphasized FEWS (217) and those that did not (72). Of the FEWS papers, the majority discussed the importance of community and stakeholder engagement [23], reviewed papers that included community and stakeholder engagement [2,27-29], or described how their model [30-32], game [33-36] or other tool [37-41] would improve the ability of stakeholders or communities to visualize the nexus or make decisions. Neither stakeholders nor communities were involved in the research described in these papers. For papers that were not FEWS related, we selected those that proposed a framework or conceptual map for stakeholder or community engagement. Those papers are described in Section 2.2 below.

Two-hundred seventeen (217) of the papers we identified were FEWS related but, of those, only 45 reported that people other than the research team were involved in their study in some way. However, designation of the level of involvement and/or the identity of communities or stakeholders in many of the papers was made difficult by the variability among papers in the description of these details. In all but a few, community and stakeholder engagement was not the focus of these papers. In some cases, at least two papers were written on different aspects of community and stakeholder engagement in one research project, and these papers together provided a more comprehensive description of the level of engagement for the research project [3,31,42-51]. We counted these linked papers as one since they described one research project.

Of those 45 papers, 20 used questionnaires, surveys, in-person interviews, or focus groups to gather data and reported it as community or stakeholder engagement. Data gathered included household consumption habits [52,53], nexus research questions [54-56], descriptions of the meaning of the word "nexus" [57,58], attitudes about community and stakeholder engagement [59], system indicators [60], interactions among nexus components [61], relative resilience [59], and research priorities or gaps where research was needed [31,50,62]. Although survey participants may have been stakeholders in the sense that they had an interest in the system in question, they were not involved in guiding or critiquing the research project in any meaningful way and served only to provide data for research.

The framework suggested by Ghodsvali et al. [4] was used to categorize community and stakeholder engagement as nominal, instrumental, representative or transformative. They defined nominal engagement as little more than display only to give legitimacy to plans and does not lead to any change (which we interpreted to mean that communities or stakeholders may have been interviewed to provide data or information, but were otherwise not engaged in the project). Instrumental engagement was defined as a means towards the efficient use of the skills and knowledge of communities and stakeholders; 
representative as giving communities and stakeholders a voice in decision-making and implementation of policies that affect them; and transformative as focusing on the empowerment of involved communities and stakeholders. Using this framework, we defined data gathering as nominal, sometimes called consultative $[16,63]$ because it is unlikely that this level of engagement contributes to beneficial outcomes in FEWS. A project could use more than one of these engagement types, for example, there could be nominal engagement for some communities or stakeholders and then more engaged approaches for other communities and stakeholders or parts of the overall engagement process.

Fourteen of the 45 papers identified stakeholders narrowly, as experts-including government, business, or NGO employees directly engaged in the nexus. Only 11 papers included communities and stakeholders who were outside of these definitions, including farmers, fishers, water-users, people displaced by dams, etc. These studies also tended to incorporate, or at least attempt to incorporate, very diverse perspectives throughout the project. In only three papers did researchers report that they had included diverse communities and stakeholders in the development of research questions or the research proposal $[44,64,65]$. Several papers stated that they had significant community and stakeholder engagement but did not describe or were vague about the engagement or did not describe the identities of their communities or stakeholders, and we assumed that they were experts only, as that is the predominant practice.

\subsection{Frameworks Supporting Best Practices in Community and Stakeholder Engagement in FEWS}

A framework for developing and applying best practices for community and stakeholder engagement in FEWS was distilled from a review and meta-synthesis of a broad range of existing frameworks, models, and reviews developed in multiple disciplines over the last two decades (Table 1). Meta-synthesis is a mixed methods approach that integrates results from a number of different but interrelated qualitative or quantitative studies using an interpretive, rather than an aggregating, approach $[66,67]$. The meta-synthesis used here is built on 24 reviews, models, frameworks, and toolkits for stakeholder engagement published since 2004, which was selected as a beginning year because this was the first year the authors were able to find a robust framework for best practices (as opposed to theoretical models). Using the 289 papers identified in Section 2.1, those papers that proposed a framework or conceptual model of stakeholder and community engagement were extracted. The authors defined frameworks or conceptual models as describing a set of lessons, guidelines, or practices. These were used as a starting point to synthesize frameworks and models of community and stakeholder engagement. There was a paucity of frameworks for stakeholder engagement in this peer-reviewed FEWS literature, so we did not restrict our search to FEWS literature. This subset was expanded by snowballing relevant literature cited in those articles, that is, reviewing the literature cited section of each article and identifying additional articles that included a framework. One in review manuscript and one in press manuscript that contained frameworks, which were identified in FEWS research coordination networks, were also included. These papers were also fully read. From this, the common practices described in these papers were extracted and enumerated. After identification of the reviews, models and frameworks, the authors identified key themes in papers and indicated the number of papers that repeated these themes as important (Table 1 and Supplementary Materials, Table S1). This resulting framework for community and stakeholder engagement in FEWS is referred to as the EngageINFEWS framework.

Existing conceptual frameworks and models for community and stakeholder engagement were found in fields as diverse as climate change [24], education [21], environmental management [16,68-71], Indigenous engagement [72-74], invasive species management [75,76], landscape sustainability [13,77], public health [6,19], urban development [9], and water governance and management $[25,63,72,73,78]$. In the nexus field of FEWS, there were also a few recent models $[3,4,46,74]$. Individually, each study or review provides one or more valuable characteristic, dimension, or element of practice in community and 
stakeholder engagement that are applicable to FEWS research and practice (Table 1). Other conceptual frameworks and models do not explicitly deal with practices in community and stakeholder engagement but rather with transdisciplinary co-production in areas of environmental science and management that are relevant to FEWS e.g., [79]. Any frameworks that did not discuss, explore, or propose one or more practice in community and stakeholder engagement were not considered.

The array of conceptual frameworks, models, and toolkits dealing with best practices span a range of theoretical foundations including adaptive management theory [75,76], collective action [25], collaborative governance and management [68], community capacity [25,70,73], educational theory [21], decolonizing and Indigenous methodologies [72,73], grounded theory [69], knowledge exchange [7], participatory action and management [6,80], social learning $[25,78]$, sustainability theory $[13,74]$, and transdisciplinarity and transdisciplinary co-production $[4,9,24,71,77]$. Our conceptual model relies heavily on fields outside of FEWS because conceptual models and frameworks papers are more developed and robust in other fields. Consistent with the emerging work in community and stakeholder engagement for FEWS, the dominant theoretical foundation adopted for the proposed framework is transdisciplinarity and is related to efforts in transdisciplinary co-production.

The set of reviews, frameworks, and models that were relevant (Table 1) used various methods to identify practices in community and stakeholder engagement. Many studies relied on systematic literature reviews from their relevant domains of interest $[4,16,19,24,25,69,76]$ and casestudy reviews $[3,9,21,73,75,78,80,81]$. Frequent author experience with community and stakeholder engagement was an important method for distilling best practices $[13,21,70,73,77,81]$, while other research was based on questionnaire surveys [7,71], workshops $[46,75,82]$, or systematic mapping review [68].

In determining which themes to include within the framework, we identified the most ubiquitous practices for supporting community and stakeholder engagement, which included the importance of understanding, documenting, and leveraging the local context of the problem or place in question, and engendering and supporting sharing of values, respect, and trust in the engagement process (Table 1 and Supplementary Materials, Table S1). Other important practices concerned collaborative power-sharing, co-ownership of the engagement process, and co-generation of knowledge and outcomes (Table 1).

\section{A Conceptual Framework for Community and Stakeholder Engagement in FEWS}

The EngageINFEWS framework comprises ten characteristics or elements (Table 1, Figure 1) identified in our meta-synthesis. FEWS issues and efforts have a particularly important meaning to Indigenous communities and tribes in countries such as Australia, Canada, New Zealand, and the United States owing to how closely some of these communities' livelihoods and cultures are tied to water and interwoven with food security. Consequently, the EngageINFEWS framework incorporates aspects of Indigenous and tribal engagement for several elements in the framework (Table 1 and Supplementary Materials, Table S1). A full synthesis of models, frameworks and toolkits is included in the Supplementary Materials. However, our synthesis of this Indigenous literature is not comprehensive because it is beyond the scope of best practices in FEWS research. 
Table 1. Summary of frameworks and conceptual models supporting best practices in community and stakeholder engagement applicable to food, energy, and water systems science.

\begin{tabular}{|c|c|c|c|c|c|c|c|c|c|c|}
\hline \multirow[b]{2}{*}{ Reference } & \multirow{2}{*}{ 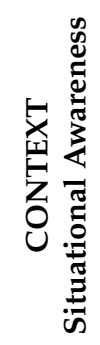 } & \multirow{2}{*}{ 党 } & \multicolumn{5}{|c|}{ ENGAGEMENT PROCESS } & \multirow{2}{*}{ 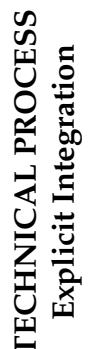 } & \multicolumn{2}{|c|}{$\begin{array}{l}\text { MONITORING } \\
\text { PROCESS }\end{array}$} \\
\hline & & & 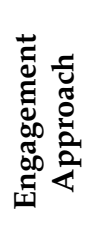 & 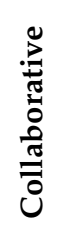 & 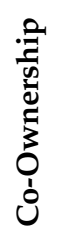 & 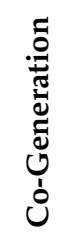 & 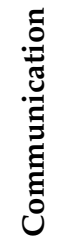 & & 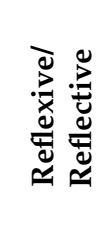 & 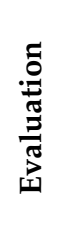 \\
\hline
\end{tabular}

\begin{tabular}{|c|c|c|c|c|c|c|c|c|c|c|}
\hline Fazey 2004 & $\checkmark$ & $\checkmark$ & $\checkmark$ & & & & & & $\checkmark$ & \\
\hline Reed 2008 & $\checkmark$ & $\checkmark$ & $\checkmark$ & & $\boldsymbol{v}$ & & & $\checkmark$ & & \\
\hline Ahmed \& Palermo 2010 & $\checkmark$ & $\checkmark$ & $\checkmark$ & $\checkmark$ & $\checkmark$ & $\checkmark$ & $\checkmark$ & & & \\
\hline Phillipson et al. 2012 & & & $\checkmark$ & & & & & & & \\
\hline Polk 205 & & $\checkmark$ & & $\checkmark$ & & $\checkmark$ & & $\checkmark$ & $\checkmark$ & $\checkmark$ \\
\hline Chief et al. 2016 & $\checkmark$ & $\checkmark$ & & $\checkmark$ & $\boldsymbol{v}$ & $\checkmark$ & $\checkmark$ & & & $\checkmark$ \\
\hline Talley et al. 2016 & $\checkmark$ & $\checkmark$ & & & $\boldsymbol{v}$ & & & & $\checkmark$ & \\
\hline Gagnon et al. 2017 & $\checkmark$ & $\checkmark$ & $\checkmark$ & $\checkmark$ & $\checkmark$ & $\checkmark$ & & & $\checkmark$ & \\
\hline Haddaway et al. 2017 & $\checkmark$ & $\checkmark$ & & & & & $\checkmark$ & & & $\boldsymbol{v}$ \\
\hline Howarth \& Monasterolo 2017 & & $\checkmark$ & & $\checkmark$ & & $\checkmark$ & & $\checkmark$ & $\checkmark$ & \\
\hline Djenontin \& Meadow 2018 & $\checkmark$ & $\checkmark$ & & $\checkmark$ & & & & & & \\
\hline Hoolohan et al. 2018 & & & & & & & & $\checkmark$ & & \\
\hline Khodyakov et al. 2018 & $\checkmark$ & $\checkmark$ & $\checkmark$ & & & & $\checkmark$ & & $\boldsymbol{V}$ & $\checkmark$ \\
\hline $\begin{array}{l}\text { Novoa et al. 2018; } \\
\text { Shackelton et al. } 2019\end{array}$ & $\checkmark$ & $\checkmark$ & & $\checkmark$ & & $\boldsymbol{v}$ & & $\checkmark$ & & \\
\hline Reed et al. 2018 & $\checkmark$ & $\checkmark$ & $\checkmark$ & $\boldsymbol{v}$ & $\boldsymbol{\nu}$ & & & & & \\
\hline Wehn et al. 2018 & & $\checkmark$ & & & & $\checkmark$ & & & & \\
\hline Dale et al. 2019 & $\checkmark$ & $\checkmark$ & $\checkmark$ & $\checkmark$ & $\checkmark$ & & $\checkmark$ & & & \\
\hline Ghodsvali et al. 2019 & & $\checkmark$ & $\checkmark$ & & & & & & & \\
\hline Jackson et al. 2019 & $\checkmark$ & $\checkmark$ & $\checkmark$ & $\checkmark$ & $\boldsymbol{V}$ & $\checkmark$ & & & & \\
\hline Thizy et al. 2019 & $\checkmark$ & $\checkmark$ & $\checkmark$ & & $\boldsymbol{v}$ & & & $\checkmark$ & $\checkmark$ & $\checkmark$ \\
\hline Feist et al. 2020 & & $\checkmark$ & $\checkmark$ & $\checkmark$ & & $\checkmark$ & & & & \\
\hline Nordstrom et al. 2020 & $\checkmark$ & $\checkmark$ & $\checkmark$ & & & $\checkmark$ & & & & \\
\hline Steger et al. 2021 & $\checkmark$ & $\checkmark$ & & & & $\checkmark$ & $\checkmark$ & & $\checkmark$ & \\
\hline Eaton et al. In review & & $\boldsymbol{v}$ & & & & $\boldsymbol{v}$ & & $\boldsymbol{v}$ & & \\
\hline
\end{tabular}




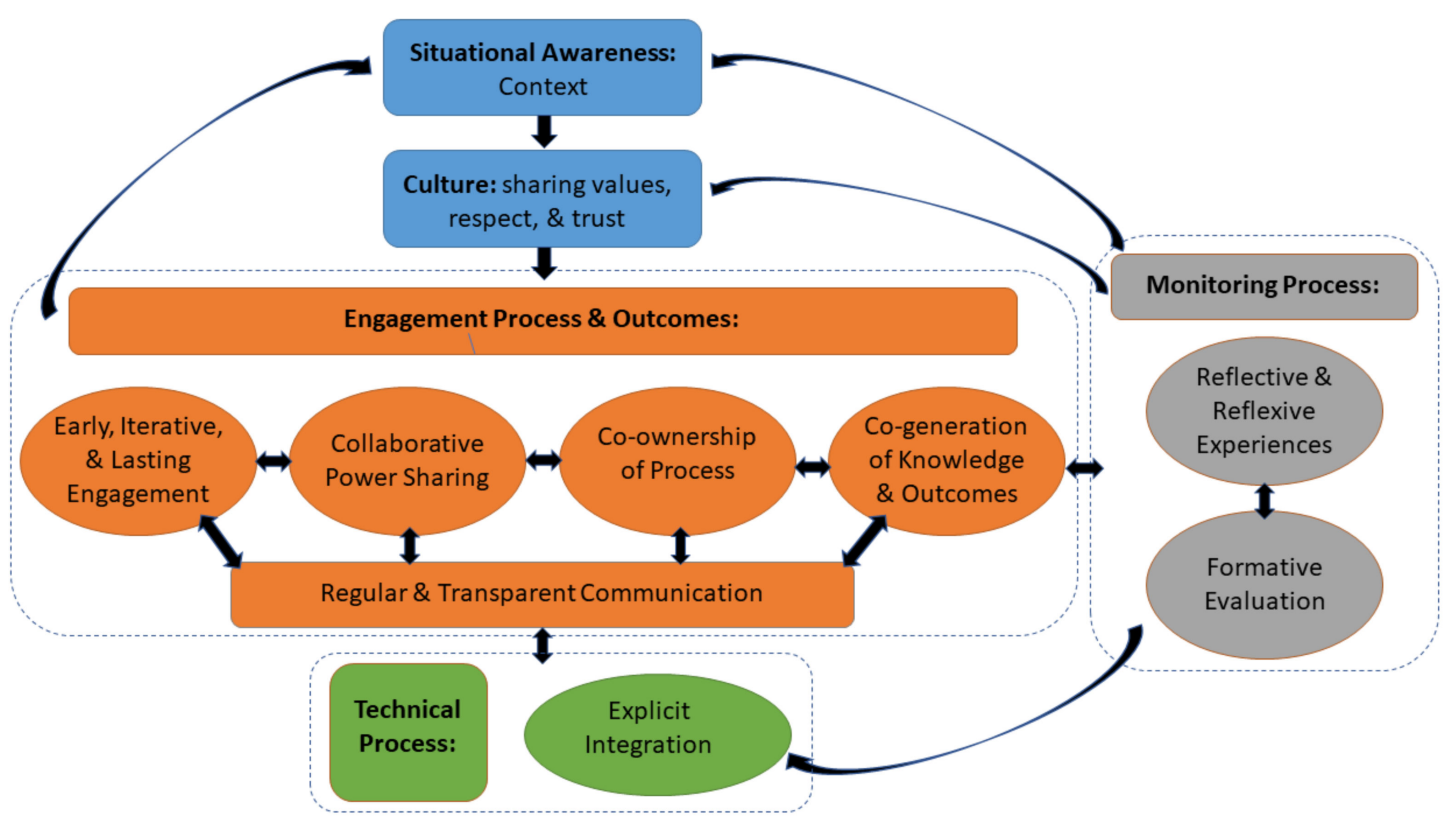

Figure 1. Diagram of the EngageINFEWS conceptual framework for best practices in community and stakeholder engagement in food, energy, and water systems science.

The ten characteristics of community and stakeholder engagement (Table 1) distilled through the meta-synthesis are conceptually linked as engagement, technical, and monitoring processes (Figure 1 and Supplementary Materials, Table S1). These processes are dependent on the situational awareness of a FEWS place or problem, and a culture of sharing values, respect, and trust (Figure 1), that is, community and stakeholder engagement is predicated on situational awareness, or context, as a starting condition for engagement. The engagement process is a function of the frequency and duration of engagement, collaborative power sharing, the co-ownership of the engagement process, and the co-generation of knowledge and outcomes. Each of these characteristics of community and stakeholder engagement are not necessarily independent dimensions, rather it is recognized that these characteristics are interrelated. Explicit methods of integration of data, perspectives, and knowledge are characterized as a technical process since analytical, quantitative, and qualitative methods may be useful here. The framework is inherently iterative so that the initial context that supports the engagement process may itself change through engagement.

\subsection{Situational Analysis}

A theme identified as critical to successful engagement processes in the papers is being fully cognizant of the local context, that is, situational awareness (Table 1). Situational awareness encompasses the perception of the elements in the environment within a specified time and space, the understanding of their meaning, and the projection of their relevance in the near future [83]. Situational awareness is particularly important in FEWS because energy, food and water systems are highly context specific and locally-scaled. For example, in non-agricultural contexts, energy-water interactions will be more important than Food-Water connections. It includes recognizing an identified need for deliberative engagement of stakeholders and community members in FEWS research, clearly defining project objectives, and using contextually relevant methods [69,80].

Situational awareness requires attentiveness to the diversity of worldviews and cultural experiences represented by the stakeholders and communities being engaged. In contexts involving Indigenous communities and sovereign Tribal Nations, engagement must also include involvement of Indigenous peoples in research whenever possible, as well as understanding their unique status and perspectives. Lukaweiki et al. [84] aptly stated that: "Indigenous groups are often still addressed as one of many stakeholder groups, 
without recognizing their status as self-determining nations with governance structures that were in place long before the arrival of settler institutions [85]. The distinction between rights-holders and stakeholders is more than just semantic. To truly respect Indigenous rights, governments must collaborate with Indigenous peoples in ways that recognize their sovereignty and right to self-governance [84] pp. 5-6, [86]."

Strategies for developing situational awareness include building on existing community partnerships, engaging a mix of project champions in the community, and generating broad support from community leaders [19]. Reed et al. [16] refer to "engagement as context" to highlight the importance of fully understanding local context to support stakeholder engagement and design of the engagement process. Examples of this approach in the FEWS literature include those who involved diverse stakeholders in Cambodia to encourage collective problem solving around water use and farming [19]. The researchers were aware of cultural resistance to engaging people other than experts and assessed their success at overcoming this barrier at the end of the study. Lehmann [48] involved farmers, students, and other water users in reducing blue water consumed to advance a shift in attitudes about water use. With Indigenous communities, this inclusion must consider understanding the cultural context, particularly of socioeconomic disadvantage [74] and the sensitivities of including Indigenous knowledge [72]. Gagnon et al. [73] highlight the importance and need for opening up space and time for Indigenous voices to influence research design and practice.

\subsection{Sharing Values and Respect}

The most commonly reported characteristic for successful community and stakeholder engagement across multiple frameworks and conceptual models in various domains was fostering an appreciation of values, respect, and trust among stakeholders (Table 1). This characteristic includes establishing a culture of empowerment, trust, and equity [69]. There is no quick fix for creating this type of culture rather it comes, in part, as a result of the personal attitudes and empathy that a project lead can impart. Some approaches that can be helpful in promoting a respectful culture comprise using an encompassing definition of stakeholders to engage broadly, including minority groups, in making research relevant to participant priorities, attempting to mitigate potential bias in stakeholder engagement, providing opportunity for stakeholders to share control over the process [87], and incorporating diverse perspectives equitably $[6,19,70]$. Emphasizing listening, inclusion of Indigenous priorities, careful trust-building, and use of culturally appropriate methods are important for Indigenous engagement [72-74]. This is emphasized by Chief et al. [72]:" do more listening. "(p. 1).

Recognition of others' values and demonstration of respect is apparent though the engagement processes of collaboratively defining issues, priorities, problem formulation, project goals, and research questions with stakeholders [9,16,24,71]. Reed et al. [16] refer to "engagement as design" to encompass the value of multiple stakeholder perspectives in a well-designed engagement process. A core approach to engagement as design is aiming for a stakeholder group that is fully representative of the place or problem $[4,69,80]$. This process includes matching representation of stakeholder interests to the spatial scale of the project goals or issues [16]. Ideally the engagement process incorporates a representative group of stakeholders, stakeholder groups, or sample of stakeholders. However, where identifying a representative group is not possible, it may suffice to have a stakeholder group that is indicative of the community or landscape. Two FEWS projects that have advanced efforts toward shared values and respect are Ferguson et al. [44], and Hargrove and Heyman [65], which all report extraordinary efforts and difficulties of developing respect in particular. In FEWS projects, attention to this theme could enhance the adoption of policies or other solutions identified to address FEWS problems identified in the research [88]. 


\subsection{Early, Iterative, and Lasting Engagement}

A key to the entire process of community and stakeholder engagement is initiating the engagement as early as possible, ideally in the proposal development stage, creating repeated engagement opportunities, and sustaining the engagement process, ideally beyond the project funding cycle. Engaging stakeholders in dialogue as early as possible in a project assists with developing shared goals (see Section 3.2 above) and the co-production of outcomes (see Section 3.6 below). By designing an iterative engagement process, it becomes possible to work with stakeholders to refine, validate, expand, and test the knowledge and ideas generated $[13,21]$. The iterative nature of good engagement processes requires a sustained effort and careful facilitation [74,89], and it is important to commit to and build both long-term and genuine relationships [73]. Iterative improvement and repeated, intentional engagement of stakeholders and community members in the co-creation of knowledge is integral to many different theoretical and practical frameworks such as social-ecological systems science, community-engagement, public participation in research, alternative futures scenario modeling and FEWS projects. FEWS problems tend to be wicked problems without a single ideal solution, so it is important to engage early and over time as challenges evolve and change. Establishing lasting engagement (e.g., beyond a research grant funding cycle) indicates trust and relationship building that is not purely transactive while also allowing for outcomes that might not emerge from a project during that standard 3- or 5-year grant cycle.

\subsection{Collaborative Power Sharing}

Managing the power dynamics among stakeholders or stakeholder groups can allow all contributions to be valued [90]. In FEW systems, power dynamics vary among federal, state and local actors and as local actors often have unique insight into which solutions will more likely be adopted, and Indigenous communities are often water rights holders and major land-owners, so managing dynamics to encourage all contributions is essential. While less commonly noted in the frameworks reviewed, acknowledging the impact of power dynamics can ensure that they are effectively managed using collaborative processes, facilitative methods, and consensus building among stakeholders $[6,9,13,16,65,75]$.

Power sharing is the foundation of meaningful stakeholder and community engagement. Addressing power dynamics and flattening hierarchies to share power is one of the most important considerations when undertaking any type of collaborative process. However, external factors, such as existing law or regulation, agency rules, and other forces can shape the extent to which power and decision-making can be evenly distributed among participants. Attempts to share power are essential, as is transparency regarding equality in decision-making power and participants' roles. Power sharing and avoidance of misappropriation of traditional knowledge are longstanding concerns for Indigenous peoples; there must be a clear understanding in advance of how knowledge will be used and shared and where decolonizing and Indigenous methodologies can facilitate diverse ways of knowing [72,73]. It is one of the most important considerations when undertaking any type of collaborative process, especially when power cannot, by law, rule, or for any other reason, be evenly distributed among participants. Being clear about inequality in decision making and clear about all participants' roles is imperative.

\subsection{Co-Ownership of Process}

Closely related to power dynamics among stakeholders is the creation of co-ownership of the project or study process among stakeholders and researchers. Co-ownership can be developed by explicitly documenting the purpose and extent of stakeholder engagement, including their level of control on research and engagement processes, and over project outcomes $[6,69,82,89]$. This practice has been termed "engagement as democracy" by Reed et al. [16]. In particular, roles and responsibilities must be defined clearly and carefully in Indigenous communities, and ownership of data and knowledge must be 
clearly understood [72,73]. Researchers should also acknowledge and comply with tribal protocols in engaging Indigenous communities [72].

\subsection{Co-Generation of Knowledge and Outcomes}

The ultimate value of stakeholder engagement in FEWS science is that it leads to beneficial outcomes for society as a whole but more specifically to the community and stakeholders concerned. These benefits have been referred to as the usability that arises from co-production $[9,46]$ or the transformative capacity of outputs and outcomes that occur through the project. Approaches that support the usability from co-produced or co-generated knowledge include promoting social learning and understanding with stakeholders, exploring practical and policy suggestions for improving engagement, creating opportunities to build capacity at individual and community levels, and using relevant timescales that support decision-making $[6,25,46,75,76,91]$. The scope and type of outcomes sought should be agreed to with the community [74]. If a methodology focused on social justice is incorporated and Indigenous interests are braided into the results, the research should give back to the community $[72,73]$.

\subsection{Technical Process: Explicit Integration of Stakeholder Knowledge and Science}

Stakeholder engagement in FEWS frequently, if not always, deals with projects in which interdisciplinary and transdisciplinary relationships, processes, data, and analyses are essential. Therefore, the engagement process for FEWS science should connect to, and be supported by, the explicit integration of social, physical, ecological, spatial, and temporal approaches. Such synthetic or integrative approaches could include synthesis of local and scientific knowledge [69,92]; practice-based and scientific perspectives [9,75]; incorporation of Indigenous knowledges [72,73,93]; integration of computational model outputs and scenario narratives [3]; incorporation of multi-scalar and inter-scalar relationships across individual, collective, and network levels [3,25,65]; interactive posters as a means for enhanced communication and learning [94]; multiple spatial scale analyses [95]; actor-resource-dynamics-interaction approaches [12]; artificial intelligence and big data analytics [96]; and landscape social-metabolism approaches [97]. These approaches can be applied to support the co-production of knowledge with stakeholders and communities. This integration can be characterized as a technical process in the framework (Figure 1, see Section 3.11 below).

\subsection{Reflective and Reflexive Experiences}

Best practices can and should be judged against current and past practices within the communities that conduct research and are affected by those research activities $[21,71,80]$. Reflexivity, or critical reflection, of researcher successes and failures, stakeholder input in the engagement process, scrutiny of which values, priorities, worldviews, and knowledge are included and excluded, and the potential effectiveness of best practices in community and stakeholder engagement are crucial to the implementation of FEWS research and outcomes [23,74]. A critical part of developing best practices is the sharing of experience, both positive and negative, about engaging with communities in the process of conducting FEWS research. Reflective approaches include acknowledging and being prepared to discuss uncertainties, risks, and shortcomings that arise in the engagement process and may be present in co-produced knowledge [19,82].

\subsection{Regular and Transparent Communication}

Good communication among stakeholders and among stakeholders and scientists helps with the stakeholder engagement process (Sections 3.2-3.5) and contributes to cogeneration of knowledge (Section 3.6). Communication with stakeholders that is regular [19], transparent [13,70], and continuous [6] all contribute to strong engagement processes. This requires project leads or facilitators to provide opportunities for communication, and for both sharing and listening [25]. Transparency in communications and 
throughout the process is especially important in Indigenous communities [72-74] and may require translation to native languages. In FEW systems, regular communication can help direct research away from mistaken assumptions or modeling attempts and toward a more accurate and efficacious suite of solutions and proposed policies.

\subsection{Evaluation}

An additional element that is included in this framework and in a couple of other models is the measurement and assessment of best practices (Table 1). The formative evaluation of the engagement process and its impacts, including demonstration of the success of both process and outcomes, is an essential element in a robust framework of practice $[9,19,63,90]$. Each best practice that is identified should be evidence-based and have identified metrics for the measurement of impacts, outcomes, and implementation. Borrowing from citizen science principles, the evaluation of community and stakeholder engagement practices can be considered along three dimensions: (i) scientific impact; (ii) learning and empowerment of participants, and (iii) impact for wider society [98]. Any evaluative dimension of a best practice can be assessed by defining a set of possible and desired outcomes (i.e., markers or goals), tracking features of engagement that might determine these outcomes (i.e., metrics or indicators), and identifying how a given engagement strategy should achieve the intended outcome (i.e., mechanisms) [19]. Evaluation should also be participatory, engaging all participants in the research [74]. In this schema, metrics are likely to be quantitative measures, while markers and mechanisms are likely to be qualitative measures. In FEWS and all other frameworks, little improvement is possible without robust evaluation.

\subsection{The EngageINFEWS Conceptual Framework}

Collectively, these ten characteristics (Table 1) define an iterative framework for developing and understanding best practices for community and stakeholder engagement (Figure 1). The framework comprises a set of three connected processes: the engagement process, technical process, and monitoring process (Figure 1).

\section{Discussion}

The importance of stakeholder engagement in FEWS research is highlighted by the substantial number of papers that refer to stakeholder or community engagement (217), in many cases acknowledging that engagement is essential. However, that can be contrasted with only twenty percent of papers (45) that provided evidence of actual engagement with stakeholders in research in some manner. This review has revealed a pattern of recognition of stakeholder engagement importance, whereas the integration of engagement into research (based on a lack of describing engagement methods and outcomes in papers) lags behind significantly.

The integration of stakeholders into FEWS research projects tends to be superficialthe majority of the 45 papers involving stakeholders reported only that researchers had conducted a survey, distributed questionnaires or engaged focus groups to identify research questions, define nexus, or gather data. Using the framework proposed by Ghodsvali et al. [4], much of the engagement that is reported is probably nominal, or at best, instrumental. As noted above, there was significant variation in descriptions of stakeholder engagement, with few projects describing engagement over the course of a research project. Short-handed descriptions may have resulted in lower counts of the level of stakeholder engagement than have actually occurred in the FEWS research community. Nonetheless, it has been easier for FEWS researchers to discuss the importance of SE than to incorporate it into their research or to describe it in peer-reviewed papers. The relatively low level of actual co-production focused approaches to FEWS research points to the need for better guidance and help on how to develop good engagement practices.

Another notable pattern in the FEWS literature is that most stakeholder engagement has involved experts, which we defined as academics, governmental officials, and NGO or 
business employees who worked within one of the nexus systems. Very few papers (11) including stakeholders outside of government, academia, or business and even fewer have reported involving Indigenous communities in research. One of the stated goals of nexus research is to couple research and policy-making in order to effect change in a system. To accomplish that goal, there is good reason to broaden definitions of "stakeholders," because the day-to-day decisions and behaviors of, for example, farmers, households, and municipalities have a significant impact on FEWS (as described in Section 3).

The literature and theory of stakeholder engagement is well advanced in disciplines such as natural resource management, environmental management and planning, education, and business. This literature contributed significantly to the synthesis supporting the conceptual framework for best practices in stakeholder and community engagement in FEWS research (Table 1). The conceptual framework for FEWS research includes ten elements (Table 1 and Figure 1). Of those ten, explicit integration of stakeholder knowledge and science is the factor most represented in the FEWS projects reviewed since 34 of the 45 papers that involved stakeholders described administering questionnaires, surveys, or focus groups to answer research questions, and that knowledge was generally integrated into the research. The majority of FEWS papers described development of a model, game, or tool to advance stakeholder understanding of the interactions at the nexus, and thus, many of the other nine characteristics are rarely described in individual FEWS projects. Several of the studies that integrated stakeholders into the research reflected some of these practices. However, only two cases were found that reported on evaluation.

Central to best practices for stakeholder and community engagement is establishing and maintaining a culture of sharing values, respect, and trust (Table 1, Figure 1). As noted, this does not come easily and points to the critical role of facilitators, whether the project lead or some other trusted individual with the requisite skill set to facilitate a diverse set of stakeholders. While the framework describes approaches that can help build respect, for example, who promotes or leads is not as obvious. Recent efforts in transdisciplinary curriculum point to team-based facilitation and conflict-resolution training [99] as a potential approach to enhance an individual's skill set. Successful engagement practices are served by identifying who is responsible for playing the role of facilitator in fostering these approaches and extends to other critical practices, for example, balancing power differentials.

Evaluating and measuring success for transformative outcomes in community and stakeholder engagement is incorporated in the EngageINFEWS framework as the monitoring process (Figure 1) comprising reflective and reflexive experiences as well as formal evaluation. Acknowledging the finding above concerning the paucity of projects reporting evaluation as part of engagement processes, there is a clear need for sustained efforts to develop and incorporate evaluation into projects. A starting point for evaluative processes can be found in efforts to advance citizen involvement in water quality projects [63] that points to the need to effectively plan with the communities by considering questions such as what are the current social, ecological, and institutional conditions; what would the community like to change; what do we know about those changeable things at this point in time, and; how can we collaboratively track them throughout our work together?

One key lesson from this review is that language matters. Language plays a role in reflecting worldviews and perpetuating narrowness and exclusion in worldviews encompassed in FEWs science. The review presented above was not entirely inclusive of key literature from Indigenous scholars and scholarship. Many others work on and write about FEWS science but chose to do so using alternative terminology from FEWs language and language of "stakeholders." Matters associated with sovereignty, both Tribal and First Nations sovereignty and rural community sovereignty, specifically, matters situated at the FEWS nexus, were captured to a limited extent in this review. More often, Indigenous land and life-the source of all food, energy, and water-are articulated as an inseparable nexus. Thus, there is a need to be attentive to the language used in literature searches moving forward, because languages reflect worldviews, and narrow language will perpetuate 
narrow worldviews and exclusive scholarship. This lesson also suggests a need for future work to explore how terminology varies across different scholarly and cultural contexts in relation to FEWS science and engagement, and most importantly, a need to be reflexive, iterative, and adaptive when applying the framework described above to Indigenous and other contexts engaging communities in nexus research across FEW systems.

\section{Conclusions-Where to Next}

Translating best practices to achieve transformative outcomes from community and stakeholder engagement in FEWS science requires both thinking big and thinking small. Thinking big points to the broad systems-level thinking inherent in FEWS research where food systems, energy systems, and water systems are individually broad in scope and of societal importance but are magnified further when considering the nexus level understanding of FEWS. Thinking big in FEWS science is characterized by the emphasis on computational modeling as a common approach to FEWS research [100-102] and by the applicability of complex systems thinking [103,104]. Thinking small acknowledges the vital link in translating broad scale thinking and modeling to relevance at local and community user scales including to support efforts focused on identifying and developing solutions to FEWS issues and challenges. The EngageINFEWS conceptual framework (Figure 1) is advanced as a step toward achieving transformative outcomes in engagement efforts that bridge thinking big to thinking small. This advancement occurs first via situational awareness of the local context for a project as a basis for determining the engagement approach and its design, including historical, cultural, ecological, governance, and institutional contexts. Second, a culture of shared values and respect. Third, implementing an engagement process based on collaborative power-sharing, co-ownership of the project, and co-generation of knowledge and outputs. Fourth, a technical process that includes explicit integration across disciplines, types of knowledge, spatial scales, and temporal scales. Fifth, a monitoring process that accommodates formative evaluation as well as reflexive and reflective experiences.

As the discussion highlights, little of the research reviewed reported bringing stakeholders on board as equal partners, as the ideal of co-generated and co-produced knowledge would be expected to do. This deficiency may, in part, be a reflection of the literature review methods failing to detect articles reporting co-production efforts. However, it is also the reality that engagement work is really hard and time intensive, and there are risks and pitfalls. For scientists, professional rewards and constraints are salient, such work is time intensive and is a constraint to pursuing traditional scientific goals. Meanwhile for stakeholders there may be distrust toward researchers who have taken much but are perceived as having given little back. The EngageINFEWS framework provides a starting point for framing community and stakeholder engagement for transformative outcomesthe principles distilled through this review better position scientists to collaborate with stakeholders in ways that are responsive to these constraints, and open opportunities for success in future engagements.

This review and the conceptual framework for best practices in stakeholder engagement point to several areas for improvement. It is important that evidence of the benefit of community and stakeholder engagement is better documented in the FEWS literature. A next step then might be to look closely at those engagement efforts that did succeed and those that did not in order to establish lessons learned for better engagement-what might success look like in FEWS specifically? Noting the discussion above regarding the constraints on scientists pursuing co-production, additional work is needed to understand the conditions that bear out co-production, including the manner by which institutions support the opportunities for pursuing co-production of knowledge. A next step then is looking not only at successful engagement but also examining successes for scientists supporting co-production against the constraints to doing so. As highlighted in the discussion there is a need for future work to explore how language across different scholarly and cultural contexts in relation to FEWS science and engagement matters. Notably there is a need 
to be reflexive, iterative, and adaptive when applying the EngageINFEWS framework to particular contexts - one future development that would be valuable is an Indigenous-led framework for engagement with Indigenous communities. There are other contexts and communities, for example farmers who use traditional practices or organic practices, that could also be examined with respect to the EngageINFEWS framework. In a nutshell, the challenge is shifting the emphasis from doing research to establishing research with and for stakeholders and rights holders-more specifically, moving from basic research to the co-production of knowledge.

Supplementary Materials: The following are available online at https:/ / www.mdpi.com/2071-1 050/13/4/2160/s1, Table S1: Meta-synthesis of models, frameworks, and toolkits supporting best practices in community and stakeholder engagement for food-energy-water systems science.

Author Contributions: Conceptualization, A.K., D.L.G., V.H.D., A.-M.M. and C.S.; methodology, A.K., D.L.G. and P.W.; formal analysis, A.K. and P.W.; writing-original draft preparation, A.K., P.W. and C.S.; writing-review and editing, V.H.D., A.-M.M., C.S., W.M.E., K.F., V.S.G., P.W., and A.K.; visualization, A.K.; supervision, A.K., D.L.G. and P.W.; project administration, A.K.; funding acquisition, A.K., D.L.G., V.H.D., A.-M.M. and C.S. All authors have read and agreed to the published version of the manuscript.

Funding: This research was funded by the National Science Foundation, grant numbers SES-1639524, OIA-1757324 through the NSF Idaho EPSCoR Program, and BCS-1856059 through the EngageINFEWS Research Coordination Network. This research was also funded in part by the Agriculture and Food Research Initiative (AFRI) Water for Agriculture grant no. 2017-68007-26584/project accession no. 1013079 from the USDA National Institute of Food and Agriculture.

Institutional Review Board Statement: Not applicable.

Informed Consent Statement: Not applicable.

Data Availability Statement: Not applicable.

Acknowledgments: Thank you to Mark Rud for the initial literature search, to Keith Kline for early discussions that contributed to the manuscript, and to Sarah Church for reviewing an earlier draft of the paper and her valuable comments. We are grateful to Lilian Alessa, James Gosz, and Julia Oxarango-Ingram for their guidance on different aspects of this work, and to Sarah Dengler for logistical support.

Conflicts of Interest: The authors declare no conflict of interest. The funders had no role in the design of the study; in the collection, analyses, or interpretation of data; in the writing of the manuscript, or in the decision to publish the results.

\section{References}

1. Scanlon, B.R.; Ruddell, B.L.; Reed, P.M.; Hook, R.I.; Zheng, C.; Tidwell, V.C.; Siebert, S. The food-energy-water nexus: Transforming science for society. Water Resour. Res. 2017, 53, 3550-3556. [CrossRef]

2. D'Odorico, P.; Davis, K.F.; Rosa, L.; Carr, J.A.; Chiarelli, D.; Dell'Angelo, J.; Gephart, J.; MacDonald, G.K.; Seekell, D.A.; Suweis, S.; et al. The Global Food-Energy-Water Nexus. Rev. Geophys. 2018, 56, 456-531. [CrossRef]

3. Hoolohan, C.; Larkin, A.; McLachlan, C.; Falconer, R.; Soutar, I.; Suckling, J.; Varga, L.; Haltas, I.; Druckman, A.; Lumbroso, D.; et al. Engaging stakeholders in research to address water-energy-food (WEF) nexus challenges. Sustain. Sci. 2018, 13, 1415-1426. [CrossRef]

4. Ghodsvali, M.; Krishnamurthy, S.; de Vries, B. Review of transdisciplinary approaches to food-water-energy nexus: A guide towards sustainable development. Environ. Sci. Policy 2019, 101, 266-278. [CrossRef]

5. FAO (Food and Agriculture Organization). Walking the Nexus Talk: Assessing the Water-Energy-Food Nexus in the Context of the Sustainable Energy for All Initiative; Environment and Natural Resources Working Paper No. 58; Flammini, A., Puri, M., Pluschke, L., Dubois, O., Eds.; FAO: Rome, Italy, 2014; pp. 1-147.

6. Ahmed, S.M.; Palermo, A.-G.S. Community Engagement in Research: Frameworks for Education and Peer Review. Am. J. Public Health 2010, 100, 1380-1387. [CrossRef]

7. Phillipson, J.; Lowe, P.; Proctor, A.; Ruto, E. Stakeholder engagement and knowledge exchange in environmental research. J. Environ. Manag. 2012, 95, 56-65. [CrossRef]

8. Kidd, S.A.; Kral, M.J. Practicing participatory action research. J. Couns. Psychol. 2005, 52, 187-195. [CrossRef] 
9. Polk, M. Transdisciplinary co-production: Designing and testing a transdisciplinary research framework for societal problem solving. Futures 2015, 65, 110-122. [CrossRef]

10. Prehoda, E.; Winkler, R.; Schelly, C. Putting Research to Action: Integrating Collaborative Governance and Community-Engaged Research for Community Solar. Soc. Sci. 2019, 8, 11. [CrossRef]

11. Bradbury-Huang, H. What is good action research?: Why the resurgent interest? Action Res. 2010. [CrossRef]

12. Villamor, G.B.; Griffith, D.L.; Kliskey, A.; Alessa, L. Contrasting stakeholder and scientist conceptual models of food-energy-water systems: A case study in Magic Valley, Southern Idaho. Socio-Environ. Syst. Model. 2020, 2, 16312. [CrossRef]

13. Dale, V.H.; Kline, K.L.; Parish, E.S.; Eichler, S.E. Engaging stakeholders to assess landscape sustainability. Landsc. Ecol. 2019, 34, 1199-1218. [CrossRef]

14. Herrero, P.; Dedeurwaerdere, T.; Osinski, A. Design features for social learning in transformative transdisciplinary research. Sustain. Sci. 2019, 14, 751-769. [CrossRef]

15. Arnstein, S.R. A Ladder Of Citizen Participation. J. Am. Inst. Plann. 1969, 35, 216-224. [CrossRef]

16. Reed, M.S.; Vella, S.; Challies, E.; de Vente, J.; Frewer, L.; Hohenwallner-Ries, D.; Huber, T.; Neumann, R.K.; Oughton, E.A.; del Ceno, J.S.; et al. A theory of participation: What makes stakeholder and public engagement in environmental management work? Restor. Ecol. 2018, 26, S7-S17. [CrossRef]

17. Ansell, C.; Gash, A. Collaborative Governance in Theory and Practice. J. Public Adm. Res. Theory 2008, 18, 543-571. [CrossRef]

18. Alessa, L.; Kliskey, A.; Altaweel, M.; Barton, M.; Bankes, S.; Bondizio, E.; Brown, D.; Feddema, J.; Grier, C.; Liu, J.; et al. Best Practices Integrating Social Sciences into Social Ecological Systems Science: Future Directions for Building a More Resilient America; Center for Resilient Communities, University of Idaho: Moscow, ID, USA, 2015; pp. 1-48.

19. Khodyakov, D.; Bromley, E.; Evans, S.; Sieck, K. Best Practices for Participant and Stakeholder Engagement in the All of Us Research Program; RAND Corporation: Santa Monica, CA, USA, 2018.

20. Bergek, A.; Norrman, C. Incubator best practice: A framework. Technovation 2008, 28, 20-28. [CrossRef]

21. Fazey, D. Developing and sharing best practice: Some key issues and principles. Learn. Teach. Action 2004, 3, 7-13.

22. Alessa, L.; Kliskey, A.; Gamble, J.; Fidel, M.; Beaujean, G.; Gosz, J. The role of Indigenous science and local knowledge in integrated observing systems: Moving toward adaptive capacity indices and early warning systems. Sustain. Sci. 2016, 11, 91-102. [CrossRef]

23. Cristan, R.; Aust, W.M.; Bolding, M.C.; Barrett, S.M.; Munsell, J.F.; Schilling, E. Effectiveness of forestry best management practices in the United States: Literature review. For. Ecol. Manag. 2016, 360, 133-151. [CrossRef]

24. Djenontin, I.N.S.; Meadow, A.M. The art of co-production of knowledge in environmental sciences and management: Lessons from international practice. Environ. Manag. 2018, 61, 885-903. [CrossRef]

25. Eaton, W.; Brasier, K.J.; Burbach, M.E.; Whitmer, W.; Engle, E.W.; Burnham, M.; Quimby, B.; Chaudhary, A.K.; Whitley, H.; Delozier, J.; et al. A conceptual model for enabling social and environmental change through stakeholder engagement in water resource management. Soc. Nat. Resour. 2021. under review.

26. Gough, D.; Oliver, S.; Thomas, J. An Introduction to Systematic Reviews, 2nd ed.; SAGE Publications Ltd.: Los Angeles, CA, USA, 2017; ISBN 9781473929432.

27. Albrecht, T.R.; Crootof, A.; Scott, C.A. The Water-Energy-Food Nexus: A systematic review of methods for nexus assessment. Environ. Res. Lett. 2018, 13, 043002. [CrossRef]

28. Endo, A.; Tsurita, I.; Burnett, K.; Orencio, P.M. A review of the current state of research on the water, energy, and food nexus. J. Hydrol. Reg. Stud. 2017, 11, 20-30. [CrossRef]

29. Yung, L.; Louder, E.; Gallagher, L.A.; Jones, K.; Wyborn, C. How Methods for Navigating Uncertainty Connect Science and Policy at the Water-Energy-Food Nexus. Front. Environ. Sci. 2019, 7, 37. [CrossRef]

30. Nie, Y.; Avraamidou, S.; Li, J.; Xiao, X.; Pistikopoulos, E.N. Land use modeling and optimization based on food-energy-water nexus: A case study on crop-livestock systems. In Computer Aided Chemical Engineering; Elsevier: Amsterdam, The Netherlands, 2018; Volume 44, pp. 1939-1944. ISBN 9780444642417.

31. Sušnik, J.; Chew, C.; Domingo, X.; Mereu, S.; Trabucco, A.; Evans, B.; Vamvakeridou-Lyroudia, L.; Savić, D.; Laspidou, C.; Brouwer, F. Multi-Stakeholder Development of a Serious Game to Explore the Water-Energy-Food-Land-Climate Nexus: The SIM4NEXUS Approach. Water 2018, 10, 139. [CrossRef]

32. Bai, C.; Sarkis, J. The Water, Energy, Food, and Sustainability Nexus Decision Environment: A Multistakeholder Transdisciplinary Approach. IEEE Trans. Eng. Manag. 2019, 1-15. [CrossRef]

33. Mochizuki, J.; Magnuszewski, P.; Linnerooth-Bayer, J. Games for Aiding Stakeholder Deliberation on Nexus Policy Issues. In Managing Water, Soil and Waste Resources to Achieve Sustainable Development Goals: Monitoring and Implementation of Integrated Resources Management; Hülsmann, S., Ardakanian, R., Eds.; Springer International Publishing: Cham, Switzerland, 2018; pp. 93-124. ISBN 9783319751634.

34. Savic, D.; Morley, M.; Khoury, M. Serious Gaming for Water Systems Planning and Management. Water 2016, 8, 456. [CrossRef]

35. Uslu, S.; Kaur, D.; Rivera, S.J.; Durresi, A.; Babbar-Sebens, M. Trust-Based Game-Theoretical Decision Making for Food-EnergyWater Management. In Advances on Broad-Band Wireless Computing, Communication and Applications; Lecture Notes in Networks and Systems; Barolli, L., Hellinckx, P., Enokido, T., Eds.; Springer International Publishing: Cham, Switzerland, 2020; Volume 97, pp. 125-136. ISBN 9783030335052. 
36. Uslu, S.; Kaur, D.; Rivera, S.J.; Durresi, A.; Babbar-Sebens, M. Decision Support System Using Trust Planning Among FoodEnergy-Water Actors. In Advanced Information Networking and Applications, Proceedings of the 34th International Conference on Advanced Information Networking and Applications (AINA-2020); Barolli, L., Takizawa, M., Xhafa, F., Enokido, T., Eds.; Springer International Publishing: Cham, Switzerland, 2020; pp. 1169-1180.

37. Daher, B.T.; Mohtar, R.H. Water-energy-food (WEF) Nexus Tool 2.0: Guiding integrative resource planning and decision-making. Water Int. 2015, 40, 748-771. [CrossRef]

38. Daher, B.; Mohtar, R.; Pistikopoulos, E.; Portney, K.; Kaiser, R.; Saad, W. Developing Socio-Techno-Economic-Political (STEP) Solutions for Addressing Resource Nexus Hotspots. Sustainability 2018, 10, 512. [CrossRef]

39. Cremades, R.; Mitter, H.; Tudose, N.C.; Sanchez-Plaza, A.; Graves, A.; Broekman, A.; Bender, S.; Giupponi, C.; Koundouri, P.; Bahri, M.; et al. Ten principles to integrate the water-energy-land nexus with climate services for co-producing local and regional integrated assessments. Sci. Total Environ. 2019, 693, 133662. [CrossRef]

40. Mathis, B.; Ma, Y.; Mancenido, M.; Maciejewski, R. Exploring the Design Space of Sankey Diagrams for the Food-Energy-Water Nexus. IEEE Comput. Graph. Appl. 2019, 1. [CrossRef]

41. Mroue, A.M.; Mohtar, R.H.; Pistikopoulos, E.N.; Holtzapple, M.T. Energy Portfolio Assessment Tool (EPAT): Sustainable energy planning using the WEF nexus approach-Texas case. Sci. Total Environ. 2019, 648, 1649-1664. [CrossRef]

42. Carpenter, S.R.; Booth, E.G.; Gillon, S.; Kucharik, C.J.; Loheide, S.; Mase, A.S.; Motew, M.; Qiu, J.; Rissman, A.R.; Seifert, J.; et al. Plausible futures of a social-ecological system: Yahara watershed, Wisconsin, USA. Ecol. Soc. 2015, 20, art10. [CrossRef]

43. Qiu, J.; Carpenter, S.R.; Booth, E.G.; Motew, M.; Zipper, S.C.; Kucharik, C.J.; Chen, X.; Loheide, S.P.; Seifert, J.; Turner, M.G. Scenarios reveal pathways to sustain future ecosystem services in an agricultural landscape. Ecol. Appl. 2018, 28, 119-134. [CrossRef] [PubMed]

44. Ferguson, L.; Chan, S.; Santelmann, M.V. Transdisciplinary Research in Water Sustainability: What's in it for an Engaged Researcher-Stakeholder Community? Water Altern. 2018, 11, 18.

45. Ferguson, L.; Chan, S.; Santelmann, M.; Tilt, B. Exploring participant motivations and expectations in a researcher-stakeholder engagement process: Willamette Water 2100. Landsc. Urban Plan. 2017, 157, 447-456. [CrossRef]

46. Howarth, C.; Monasterolo, I. Opportunities for knowledge co-production across the energy-food-water nexus: Making interdisciplinary approaches work for better climate decision making. Environ. Sci. Policy 2017, 75, 103-110. [CrossRef]

47. Howarth, C.; Monasterolo, I. Understanding barriers to decision making in the UK energy-food-water nexus: The added value of interdisciplinary approaches. Environ. Sci. Policy 2016, 61, 53-60. [CrossRef]

48. Lehmann, S. Implementing the Urban Nexus approach for improved resource-efficiency of developing cities in Southeast-Asia. City Cult. Soc. 2018, 13, 46-56. [CrossRef]

49. Lehmann, S. Conceptualizing the Urban Nexus Framework for a Circular Economy: Linking Energy, Water, Food, and Waste (EWFW) in Southeast-Asian cities. In Urban Energy Transition; Elsevier: Amsterdam, The Netherlands, 2018; pp. 371-398. ISBN 9780081020746.

50. Trabucco, A.; Sušnik, J.; Vamvakeridou-Lyroudia, L.; Evans, B.; Masia, S.; Blanco, M.; Roson, R.; Sartori, M.; Alexandri, E.; Brouwer, F.; et al. Water-Food-Energy Nexus under Climate Change in Sardinia. Proceedings 2018, 2, 609. [CrossRef]

51. Hoolohan, C.; McLachlan, C.; Larkin, A. 'Aha' moments in the water-energy-food nexus: A new morphological scenario method to accelerate sustainable transformation. Technol. Forecast. Soc. Chang. 2019, 148, 119712. [CrossRef]

52. Ramaswami, A.; Boyer, D.; Nagpure, A.S.; Fang, A.; Bogra, S.; Bakshi, B.; Cohen, E.; Rao-Ghorpade, A. An urban systems framework to assess the trans-boundary food-energy-water nexus: Implementation in Delhi, India. Environ. Res. Lett. 2017, 12, 025008. [CrossRef]

53. Watkins, D.; Shwom, R.; Schelly, C.; Agusdinata, D.B.; Floress, K.; Halvorsen, K.E. Understanding household conservation, climate change and the food-energy-water nexus from a transdisciplinary perspective. In A Research Agenda for Environmental Management; Edward Elgar Publishing: Cheltenham, UK, 2019; pp. 145-158.

54. Green, J.M.H.; Cranston, G.R.; Sutherland, W.J.; Tranter, H.R.; Bell, S.J.; Benton, T.G.; Blixt, E.; Bowe, C.; Broadley, S.; Brown, A.; et al. Research priorities for managing the impacts and dependencies of business upon food, energy, water and the environment. Sustain. Sci. 2017, 12, 319-331. [CrossRef]

55. Rosen, R. Water-Energy-Food Nexus. In Water-Energy-Food Nexus Stakeholder Information Sharing and Engagement Workshop; The Texas A\&M University System: College Station, TX, USA, 11 January 2018; pp. 1-73.

56. Fairbrother, A.; Muir, D.; Solomon, K.R.; Ankley, G.T.; Rudd, M.A.; Boxall, A.B.A.; Apell, J.N.; Armbrust, K.L.; Blalock, B.J.; Bowman, S.R.; et al. Toward Sustainable Environmental Quality: Priority Research Questions for North America: Priority environmental quality questions for North America. Environ. Toxicol. Chem. 2019, 38, 1606-1624. [CrossRef]

57. Cairns, R.; Krzywoszynska, A. Anatomy of a buzzword: The emergence of 'the water-energy-food nexus' in UK natural resource debates. Environ. Sci. Policy 2016, 64, 164-170. [CrossRef]

58. White, D.; Jones, J.; Maciejewski, R.; Aggarwal, R.; Mascaro, G. Stakeholder Analysis for the Food-Energy-Water Nexus in Phoenix, Arizona: Implications for Nexus Governance. Sustainability 2017, 9, 2204. [CrossRef]

59. Allen, C.R.; Birgé, H.; Angeler, D.G.; Arnold, C.A.; Chaffin, B.C.; DeCaro, D.; Garmestani, A.S.; Gunderson, L.H. Uncertainty and Trade-Offs in Resilience Assessments. In Practical Panarchy for Adaptive Water Governance; Cosens, B., Gunderson, L., Eds.; Springer International Publishing: Cham, Switzerland, 2018; pp. 243-268. ISBN 9783319724706. 
60. Dale, V.H.; Kline, K.L.; Richard, T.L.; Karlen, D.L.; Belden, W.W. Bridging biofuel sustainability indicators and ecosystem services through stakeholder engagement. Biomass Bioenergy 2018, 114, 143-156. [CrossRef]

61. Bielicki, J.M.; Beetstra, M.A.; Kast, J.B.; Wang, Y.; Tang, S. Stakeholder Perspectives on Sustainability in the Food-Energy-Water Nexus. Front. Environ. Sci. 2019, 7, 7. [CrossRef]

62. Bisaro, A.; Kirk, M.; Zdruli, P.; Zimmermann, W. Global Drivers Setting Desertification Research Priorities: Insights From A Stakeholder Consultation Forum. Land Degrad. Dev. 2014, 25, 5-16. [CrossRef]

63. Prokopy, L.S.; Floress, K. Measuring the Citizen Effect: What Does Good Citizen Involvement Look Like? In Pathways for Getting to Better Water Quality: The Citizen Effect; Wright Morton, L., Brown, S.S., Eds.; Springer: New York, NY, USA, 2011; pp. 83-93. ISBN 9781441972828.

64. Saravanamuthu, K. How risk information and stakeholder-participation affect the sustainability of collaborative decisions: A case study on how the sustainability of stakeholder decisions is affected by different levels of stakeholder participation in preparing risk informa. Bus. Strategy Environ. 2018, 27, 1067-1078. [CrossRef]

65. Hargrove, W.L.; Heyman, J.M. A Comprehensive Process for Stakeholder Identification and Engagement in Addressing Wicked Water Resources Problems. Land 2020, 9, 119. [CrossRef]

66. Walsh, D.; Downe, S. Meta-synthesis method for qualitative research: A literature review. J. Adv. Nurs. 2005, 50, 204-211. [CrossRef]

67. Urquhart, C. Meta-Synthesis of Research on Information Seeking Behaviour. Inf. Res. Int. Electron. J. $2011,16$.

68. Feist, A.; Plummer, R.; Baird, J. The Inner-Workings of Collaboration in Environmental Management and Governance: A Systematic Mapping Review. Environ. Manag. 2020. [CrossRef]

69. Reed, M.S. Stakeholder participation for environmental management: A literature review. Biol. Conserv. 2008, 141, 2417-2431. [CrossRef]

70. Haddaway, N.R.; Kohl, C.; Rebelo da Silva, N.; Schiemann, J.; Spök, A.; Stewart, R.; Sweet, J.B.; Wilhelm, R. A framework for stakeholder engagement during systematic reviews and maps in environmental management. Environ. Evid. $2017,6,11$. [CrossRef]

71. Steger, C.; Klein, J.A.; Reid, R.S.; Lavorel, S.; Tucker, C.M.; Hopping, K.A.; Marchant, R.; Teel, T.; Cuni-Sanchez, A.; Dorji, T.; et al. Science with Society: Evidence-based Guidance for Best Practices in Environmental Transdisciplinary Work. Glob. Environ. Change 2021, in press.

72. Chief, K.; Meadow, A.; Whyte, K. Engaging Southwestern Tribes in Sustainable Water Resources Topics and Management. Water 2016, 8, 350. [CrossRef]

73. Gagnon, V.; Gorman, H.; Norman, E. Power and politics in research design and practice: Opening up space for social equity in interdisciplinary, multi-jurisdictional and community-based research. Gatew. Int. J. Community Res. Engagem. 2017, 10, 164-184. [CrossRef]

74. Jackson, M.; Stewart, R.A.; Fielding, K.S.; Cochrane, J.; Beal, C.D. Collaborating for Sustainable Water and Energy Management: Assessment and Categorisation of Indigenous Involvement in Remote Australian Communities. Sustainability 2019, $11,427$. [CrossRef]

75. Novoa, A.; Shackleton, R.; Canavan, S.; Cybèle, C.; Davies, S.J.; Dehnen-Schmutz, K.; Fried, J.; Gaertner, M.; Geerts, S.; Griffiths, C.L.; et al. A framework for engaging stakeholders on the management of alien species. J. Environ. Manag. 2018, 205, $286-297$. [CrossRef] [PubMed]

76. Shackleton, R.T.; Adriaens, T.; Brundu, G.; Dehnen-Schmutz, K.; Estévez, R.A.; Fried, J.; Larson, B.M.H.; Liu, S.; Marchante, E.; Marchante, H.; et al. Stakeholder engagement in the study and management of invasive alien species. J. Environ. Manag. 2019, 229, 88-101. [CrossRef]

77. Norström, A.V.; Cvitanovic, C.; Löf, M.F.; West, S.; Wyborn, C.; Balvanera, P.; Bednarek, A.T.; Bennett, E.M.; Biggs, R.; de Bremond, A.; et al. Principles for knowledge co-production in sustainability research. Nat. Sustain. 2020, 3, 182-190. [CrossRef]

78. Wehn, U.; Collins, K.; Anema, K.; Basco-Carrera, L.; Lerebours, A. Stakeholder engagement in water governance as social learning: Lessons from practice. Water Int. 2018, 43, 34-59. [CrossRef]

79. Pahl-Wostl, C. A conceptual framework for analysing adaptive capacity and multi-level learning processes in resource governance regimes. Glob. Environ. Change 2009, 19, 354-365. [CrossRef]

80. Talley, J.L.; Schneider, J.; Lindquist, E. A simplified approach to stakeholder engagement in natural resource management: The Five-Feature Framework. Ecol. Soc. 2016, 21, 38. [CrossRef]

81. Chief, K.; Chischilly, A.M.; Cochran, P.; Durglo, M.; Hardison, P.; Hostler, J.; Lynn, K.; Morishima, G.; Motanic, D.; St. Arnold, J.; et al. Guidelines for Considering Traditional Knowledges in Climate Change Initiatives; Social Science Research Network: Rochester, NY, USA, 2015.

82. Thizy, D.; Emerson, C.; Gibbs, J.; Hartley, S.; Kapiriri, L.; Lavery, J.; Lunshof, J.; Ramsey, J.; Shapiro, J.; Singh, J.A.; et al. Guidance on stakeholder engagement practices to inform the development of area-wide vector control methods. PLoS Negl. Trop. Dis. 2019, 13, e0007286. [CrossRef]

83. National Research Council. Modeling Human and Organizational Behavior: Application to Military Simulations; The National Academies Press: Washington, DC, USA, 1998; ISBN 9780309060967.

84. Lukawiecki, J.; Gagnon, R.; Dokis, C.; Walters, D.; Molot, L. Meaningful engagement with Indigenous peoples: A case study of Ontario's Great Lakes Protection Act. Int. J. Water Resour. Dev. 2019, 1-16. [CrossRef] 
85. Reo, N.J.; Whyte, K.P.; McGregor, D.; Smith, M.A.; Jenkins, J.F. Factors that support Indigenous involvement in multi-actor environmental stewardship. Altern. Int. J. Indig. Peoples 2017, 13, 58-68. [CrossRef]

86. Von der Porten, S.; de Loë, R.; Plummer, R. Research Article: Collaborative Environmental Governance and Indigenous Peoples: Recommendations for Practice. Environ. Pract. 2015, 17, 134-144. [CrossRef]

87. Koontz, T.M. Social learning in collaborative watershed planning: The importance of process control and efficacy. J. Environ. Plan. Manag. 2014, 57, 1572-1593. [CrossRef]

88. Daher, B.; Hannibal, B.; Mohtar, R.H.; Portney, K. Toward understanding the convergence of researcher and stakeholder perspectives related to water-energy-food (WEF) challenges: The case of San Antonio, Texas. Environ. Sci. Policy 2020, 104, 20-35. [CrossRef]

89. Simpson, H.; de Loë, R.; Rudolph, D. Evaluating an Agri-Environmental Network and Its Role in Collaborative Problem-Solving. In Water, Energy, Food and People Across the Global South; Swatuk, L.A., Cash, C., Eds.; Springer International Publishing: Cham, Switzerland, 2018; ISBN 9783319640235.

90. Bréthaut, C.; Gallagher, L.; Dalton, J.; Allouche, J. Power dynamics and integration in the water-energy-food nexus: Learning lessons for transdisciplinary research in Cambodia. Environ. Sci. Policy 2019, 94, 153-162. [CrossRef]

91. Johnson, O.W.; Karlberg, L. Co-exploring the Water-Energy-Food Nexus: Facilitating Dialogue through Participatory Scenario Building. Front. Environ. Sci. 2017, 5, 24. [CrossRef]

92. Knox, J.W.; Haro-Monteagudo, D.; Hess, T.M.; Morris, J. Identifying Trade-Offs and Reconciling Competing Demands for Water: Integrating Agriculture Into a Robust Decision-Making Framework. Earths Future 2018, 6, 1457-1470. [CrossRef]

93. Chief, K.; Daigle, J.J.; Lynn, K.; Whyte, K.P. Indigenous experiences in the U.S. with climate change and environmental stewardship in the Anthropocene. In Forest Conservation and Management in the Anthropocene: Conference Proceedings; Sample, V.A., Bixler, R., Patrick, B.R., Eds.; US Department of Agriculture, Forest Service, Rocky Mountain Research Station: Fort Collins, CO, USA, 2014; pp. 161-176, RMRS-P-71.

94. Dale, V.H.; Kline, K.L. Interactive posters: A valuable means of enhancing communication and learning about productive paths toward sustainable bioenergy. Biofuels Bioprod. Biorefin. 2017, 11, 243-246. [CrossRef]

95. Bijl, D.L.; Bogaart, P.W.; Dekker, S.C.; van Vuuren, D.P. Unpacking the nexus: Different spatial scales for water, food and energy. Glob. Environ. Change 2018, 48, 22-31. [CrossRef]

96. Pitts, J.; Gopal, S.; Ma, Y.; Koch, M.; Boumans, R.M.; Kaufman, L. Leveraging Big Data and Analytics to Improve Food, Energy, and Water System Sustainability. Front. Big Data 2020, 3. [CrossRef]

97. Villamor, G.B.; Kliskey, A.D.; Griffith, D.L.; de Haro-Marti, M.E.; Martinez, A.M.; Alfaro, M.; Alessa, L. Landscape socialmetabolism in food-energy-water systems: Agricultural transformation of the Upper Snake River Basin. Sci. Total Environ. 2020, 705, 135817. [CrossRef] [PubMed]

98. Kieslinger, B.; Schäfer, T.; Heigl, F.; Dörler, D.; Richter, A.; Bonn, A. Evaluating citizen science: Towards an open framework. In Citizen Science: Innovation in Open Science, Society and Policy; Bonn, A., Hecker, S., Haklay, M., Bowser, A., Makuch, Z., Vogel, J., Eds.; UCL Press: London, UK, 2018; pp. 81-96. ISBN 9781787352353.

99. Kliskey, A.; Alessa, L.; Griffith, D.; Olsen, S.; Williams, P.; Matsaw, S.; Cenek, M.; Gosz, J.; Dengler, S. Transforming sustainability science for practice: A social-ecological systems framework for training sustainability professionals. Sustain. Sci. 2020. [CrossRef]

100. Tian, H.; Lu, C.; Pan, S.; Yang, J.; Miao, R.; Ren, W.; Yu, Q.; Fu, B.; Jin, F.-F.; Lu, Y.; et al. Optimizing resource use efficiencies in the food-energy-water nexus for sustainable agriculture: From conceptual model to decision support system. Curr. Opin. Environ. Sustain. 2018, 33, 104-113. [CrossRef]

101. Li, M.; Fu, Q.; Singh, V.P.; Liu, D.; Li, T. Stochastic multi-objective modeling for optimization of water-food-energy nexus of irrigated agriculture. Adv. Water Resour. 2019, 127, 209-224. [CrossRef]

102. Guan, X.; Mascaro, G.; Sampson, D.; Maciejewski, R. A metropolitan scale water management analysis of the food-energy-water nexus. Sci. Total Environ. 2020, 701, 134478. [CrossRef]

103. Dargin, J.; Daher, B.; Mohtar, R.H. Complexity versus simplicity in water energy food nexus (WEF) assessment tools. Sci. Total Environ. 2019, 650, 1566-1575. [CrossRef] [PubMed]

104. Mercure, J.-F.; Paim, M.A.; Bocquillon, P.; Lindner, S.; Salas, P.; Martinelli, P.; Berchin, I.I.; de Andrade Guerra, J.B.S.O.; Derani, C.; de Albuquerque, C.L., Jr.; et al. System complexity and policy integration challenges: The Brazilian Energy-Water-Food Nexus. Renew. Sustain. Energy Rev. 2019, 105, 230-243. [CrossRef] 